\title{
A New Reality: Experiences from Canadian Clerkship Medical Students during COVID-19
}

Jeffrey Leong,' Gurkaran S. Sarohia.'

\section{The Experience}

Medical students across the globe are being impacted by COVID-19 due to changes in teaching activities and patient care involvement. ${ }^{5}$ We are third year Canadian medical students studying at the University of British Columbia (UBC) and were in our clerkship year when the COVID19 pandemic started. We first began our clerkship in the summer of 2019 as cheerful and upbeat medical students, eager to see patients through a well-organized rotation schedule. Never would we have imagined that our lives as medical learners would have changed so drastically and suddenly. On March 11, 2020, COVID-19 was declared a pandemic by the World Health Organization.' That same day, there were 46 cases in British Columbia ( 117 cases in Canada) occurring in health regions of Vancouver Coastal Health, Fraser Health and Island Health.' We were hopeful that our clinical duties as year 3 medical students would not be impacted as we were training in a rural town located more than $700 \mathrm{~km}$ away from these cases. However, on March 17, British Columbia (BC) declared a public health emergency and soon after on March 19, clinical duties for all the year 3 and 4 medical students at UBC were suspended.' We soon saw a new reality of physical distancing measures of 2 meters being implemented, along with restrictions of mass gatherings and closure of non-essential community services.' Undoubtedly, our once cheerful and upbeat disposition faded into one of vulnerability and anxiety given the everevolving situation.

\section{Adaptations of Academic Bodies to COVID-19}

While the impact of COVID-19 on medical students has yet to be explored, one may infer that the impact of COVID-19 will be similar or worse than the 2003 SARS outbreak. One study showed that the SARS outbreak and the subsequent suspension of clinical duties for University of Toronto medical students resulted in a negative impact on medical training and significant psychological stress. ${ }^{2}$ Much like the 2003 outbreak, clinical duties for the roughly 600 year 3 and 4 medical students at UBC have been suspended during COVID-19. In fact, clinical duties have been suspended for all Canadian clerkship medical students, a decision made by the Association of Faculties of Medicine of Canada which governs all 17 Canadian medical faculties. ${ }^{3}$ As for the some 300 year 3 UBC clerkship students like ourselves, curricular changes are being undertaken and a research-based course from fourth year is being pushed up to this year. In addition, online learning has not occurred for our year 3 class and written and oral exams are cancelled.

\section{Medical Student Responsibility during COVID-19}

In past acute health care problems, medical students have been deployed to provide patient care. Events including the 1918 flu pandemic and 2010 South American earthquake and tsunami have seen medical trainees being positioned to assist with health care.4, 7 During COVID-19, we have seen Italian medical student graduation streamlined to allow for medical worker reinforcement, yet Canadian year 3 and 4 medical students are unable to participate in any clinical work. ${ }^{5}$ One may argue that this comes at an opportunity cost to our learning and conflicts with a 2007 Canadian Federation of Medical Students (CFMS) policy which stated that "efforts should be made to educate medical students about their scopes of practice and emergency procedures before a disaster or emergency occurs". ${ }^{6}$ This poses the question then of what our responsibility as year 3 Canadian medical students are during pandemics.

As year 3 medical students, we are eager to assist with the COVID-19 pandemic and have witnessed overwhelming support among our year 3 colleagues as well. Student led initiatives such as basic childcare, grocery shopping, contact tracing, 8-1-1 helpline support have been organized by medical students where many students, including ourselves, have signed up to volunteer. While not direct patient contact, we do find some sense of fulfillment in volunteer duties and paraclinical work knowing that these tasks help to alleviate some pressure off the busy health care workers.

\section{Summary}

COVID-19 has caused disruption in everyday life, including medical education. It has side-lined clinical UBC medical students and created physical distancing measures with government policies for selfisolation after return from travel.' Life as we knew it at the beginning of our clerkship in the summer 2019 has drastically changed. There are questions we still have: What are the responsibilities of Canadian medical students? Are we prepared to assist in a pandemic if it occurs again? Should there be any curricular training for pandemic management in medical school? While we are in the midst of the pandemic, there will be important lessons learned once everything settles. One of the most important lessons learned thus far is from the late Canadian physician, William Osler, and his wise words of, "Soap and water and common sense are the best disinfectants".

\footnotetext{
Medical student, University of British Columbia, Vancouver, Canada.
} 


\section{Experience}

\section{References}

1. British Columbia Centre for Disease Control. Latest case counts on novel coronavirus; 2020. Cited Apr 14, 2020. Available from: http://www.bccdc.ca/about/news-stories/stories/2020/information-on-novelcoronavirus.

2. Landis MS, Bradley JW. The impact of the 2003 SARS outbreak on medical students at the university of Toronto. University of Toronto Medical Journal. 2005; $82(3): 3-41$

3. The Association of Faculties of Medicine in Canada. Covid-19. Cited Apr 14, 2020 Available from: https://afmc.ca/en/priorities/covid19.
4. $\quad$ Reyes H. Students' response to disaster: A lesson for health care professional schools. Ann Intern Med. 2010 Nov 16;153(10):658-60.

5. Miller DG, Pierson L, Doernberg S. The role of medical students during the COVID19 pandemic. Ann Intern Med. 2020 Apr 7

6. Fabreau G, McKinney B. An ounce of preparation: Ensuring Canadian medical student preparedness for disaster At emergency. 2020. Cited Apr 14, 2020. Available from: https://www.cfms.org/files/position-papers/archived/2007-DEPPolicy-Paper.pdf.

7. Starr, I. Influenza in 1918: Recollections of the epidemic in Philadelphia. Ann Intern Med. 2006 Jul 18;145(2):138-40.

\section{Acknowledgments}

None

\section{Conflict of Interest Statement at Funding}

The Authors have no funding, financial relationships or conflicts of interest to disclose.

Author Contributions

Conceptualization: JL. Writing - Original Draft, Writing - Review At Editing: JL, and CS.

Cite as:

Leong J, Sarohia CS. A New Reality: Experiences from Canadian Clerkship Medical Students during CoVID-19. Int J Med Students. 2020 Jan-Apr;8(1):68-69.

This work is licensed under a Creative Commons Attribution 4.0 International License

ISSN 2076-6327

This journal is published by the University Library System, University of Pittsburgh as part of the Digital Publishing Program and is co-sponsored by the University of Pittsburgh Press. 